\title{
Human Papillomavirus Genotyping and E6/E7 mRNA Expression in Greek Women with Intraepithelial Neoplasia and Squamous Cell Carcinoma of the Vagina and Vulva
}

\author{
Elpida Tsimplaki, ${ }^{1}$ Elena Argyri, ${ }^{1}$ Lina Michala, ${ }^{2}$ Maria Kouvousi, ${ }^{1}$ Aikaterini Apostolaki, \\ George Magiakos, ${ }^{4}$ Issidora Papassideri, ${ }^{5}$ and Efstathia Panotopoulou ${ }^{1}$ \\ ${ }^{1}$ Department of Virology, “G. Papanicolaou” Research Center of Oncology and Experimental Surgery, \\ Regional Anticancer Oncology Hospital of Athens "St. Savvas", 171 Alexandras Avenue, 11522 Athens, Greece \\ ${ }^{2} 1$ st Department of Obstetrics and Gynecology, Alexandra Hospital, University of Athens, Vas Sofias 80, 11528 Athens, Greece \\ ${ }^{3}$ Department of Pathology, Regional Anticancer Oncology Hospital of Athens "St. Savvas", \\ 171 Alexandras Avenue, 11522 Athens, Greece \\ ${ }^{4} 1$ st Department of Gynecology, Regional Anticancer Oncology Hospital of Athens "St. Savvas", \\ 171 Alexandras Avenue, 11522 Athens, Greece \\ ${ }^{5}$ Department of Cell Biology and Biophysics, Faculty of Biology, University of Athens, Panepistimiopolis, 15784 Athens, Greece
}

Correspondence should be addressed to Efstathia Panotopoulou, epanot@tee.gr

Received 1 August 2011; Revised 19 September 2011; Accepted 20 September 2011

Academic Editor: Adhemar Longatto-Filho

Copyright ( $\odot 2012$ Elpida Tsimplaki et al. This is an open access article distributed under the Creative Commons Attribution License, which permits unrestricted use, distribution, and reproduction in any medium, provided the original work is properly cited.

\begin{abstract}
A large proportion of vaginal and vulvar squamous cell carcinomas (SCCs) and intraepithelial neoplasias (VAIN and VIN) are associated with HPV infection, mainly type 16. The purpose of this study was to identify HPV genotypes, as well as E6/E7 mRNA expression of high-risk HPVs $(16,18,31,33$, and 45) in 56 histology samples of VAIN, VIN, vaginal, and vulvar SCCs. HPV was identified in $56 \%$ of VAIN and $50 \%$ of vaginal SCCs, $71.4 \%$ of VIN and 50\% of vulvar SCCs. E6/E7 mRNA expression was found in one-third of VAIN and in all vaginal SCCs, $42.9 \%$ of VIN and $83.3 \%$ of vulvar SCCs. Our data indicated that HPV 16 was the commonest genotype identified in VAIN and VIN and the only genotype found in SCCs of the vagina and vulva. These findings may suggest, in accordance with other studies, that mRNA assay might be useful in triaging lesions with increased risk of progression to cancer.
\end{abstract}

\section{Introduction}

Human papillomavirus (HPV) infection of the female genital tract, is particularly frequent worldwide and its majority is transient, while at the same time, the persistent infections caused by the oncogenic types of HPV are responsible for cancer development. This oncogenic action of HPV is a result of the transformation ability of the high-risk (hr) HPV types' oncoproteins E6 and E7. The oncogenic properties of high-risk HPV reside in the E6 and E7 genes, which if inappropriately expressed in dividing cells deregulate cell division and differentiation [1].
The causal relation of HPV infection with development of cervical cancer has been firmly established. The same does not necessarily apply to vulvar and vaginal squamous cell carcinomas (SCCs), where HPV is responsible for only a smaller percentage, namely, $60-70 \%$ of vaginal SCCs $[2$, $3]$ and $38-75 \%$ of vulvar SCCs [2, 4]. Interestingly, HPV infection is strongly associated with intraepithelial neoplasia of the vagina (VAIN) and vulva (VIN) (93.6\% and 84\%, resp.) [5]. HPV 16 is by far the commonest HPV type identified in vaginal and vulvar SCCs and precancerous lesions [6]. The above data may vary from population to population, and to our knowledge, no such analysis has been conducted in Greece. 
The purpose of the current study was the HPV genotyping, as well as the expression of E6/E7 mRNA from the hrHPV types $(16,18,31,33$, and 45) in Greek women with VAIN, VIN, and SCCs of the vagina and vulva.

\section{Materials and Methods}

2.1. Study Population and Collection of Specimens. The sam-ple of this study consisted of 56 paraffin-embedded tissue sections of VAIN, VIN, or vaginal and vulvar SCCs obtained from the Pathology Laboratory of the Regional Anticancer Oncology Hospital of Athens "St. Savvas". The tissues were deparaffinized, and total nucleic acid was extracted using automated extraction (NucliSENS easyMAG, bioMérieux Hellas S.A). Then, genotyping of 24 HPV types was performed with microarray-based assay (PapilloCheck HPV-Screening, Greiner Bio-One $\mathrm{GmbH}$, Germany, cat no. 465 060) as well as the expression of HPV $16,18,31,33$, and $45 \mathrm{E} 6 / \mathrm{E} 7 \mathrm{mRNA}$, using the commercial real-time NucliSENS EasyQ assay (NucliSENS EasyQ HPV 1.1, bioMérieux Hellas S.A, cat no. 290003).

Although VIN terminology was changed by the International Society for the Study on Vulvovaginal Disease in 2004, we maintained the original terminology which was used during the histological diagnosis [6].

Ethical approval was granted by the ethics committee of the Regional Anticancer Oncology Hospital of Athens "St. Savvas", and all participants provided written informed consent.

2.2. Deparaffinization. Fifteen micrometer sections of paraffin-embedded tissues were deparaffinized by incubation with 100\% xylene (Applichem GmbH, Darmstadt, Germany, cat no. 10-20/21-38) at $50^{\circ} \mathrm{C}$ and washings twice with $100 \%$ ethanol (Applichem GmbH, Darmstadt, Germany, cat no. 64-17-5). Then, the pellets were dried at room temperature for 45 minutes. Finally, deparaffinized samples were digested with $100 \mu \mathrm{L}$ digestion buffer [ $1 \mathrm{~mL}$ TE buffer $1 \mathrm{X}$ (Invitrogen corp., Calif, USA, cat no. 12090-015) and $5 \mu \mathrm{L} \mathrm{50 \%}$ Tween 20 solution (Invitrogen corp., Calif, USA, cat no. 00-3005)] and $5 \mu \mathrm{L}$ proteinase $\mathrm{K}$ solution (Invitrogen corp., Calif, USA, cat no. $25530-049)$ at $65^{\circ} \mathrm{C}$ overnight. Proteinase $\mathrm{K}$ was deactivated in heat block at $80^{\circ} \mathrm{C}$ for 15 minutes.

2.3. Extraction of Nucleic Acids. Tissue samples were transferred in lysis buffer (NucliSENS lysis buffer, bioMérieux Hellas S.A, cat no. 200292) for 30 minutes, then total nucleic acid was extracted by the off-board protocol with the NucliSENS easyMAG platform (bioMérieux Hellas S.A), according to the manufacturer's instructions. The nucleic acids were eluted in $55 \mu \mathrm{L}$ of elution buffer. DNA quality test was carried out using Human Globin, Beta, Primer set kit (Maxim Biotech, Inc., South San Francisco, CA) according to manufacturer's instructions. To assess RNA integrity, $5 \mu \mathrm{g}$ of RNA per sample was separated on $1 \%$ formaldehyde-agarose gel.
2.4. HPV Genotyping (PapilloCheck HPV DNA Microarray). The PapilloCheck HPV-Screening was used. This technology is based on a DNA chip for the type-specific identification of 24 types of HPV (18 high-risk and 6 lowrisk types). E1-based PCR was performed according to the manufacturer's guidelines. For each sample, we mixed 19,8 $\mu \mathrm{L}$ PapilloCheck MasterMix, 0,2 $\mu \mathrm{L}$ HotStarTaq plus DNA polymerase ( $5 \mathrm{U} / \mu \mathrm{L}$, Qiagen, cat no. 203605), and $5 \mu \mathrm{L}$ DNA from the tissue sample. Hybridization is followed by mixing $30 \mu \mathrm{L}$ of the PapilloCheck hybridization buffer in a fresh reaction tube with $5 \mu \mathrm{L}$ of the PCR product at room temperature and transferring $25 \mu \mathrm{L}$ of the hybridization mix into each compartment of the chip. We incubated the chip for 15 minutes at room temperature in a humid atmosphere. The chip was washed in 3 washing solutions, centrifuged for 3 minutes at $5000 \mathrm{rpm}$, and scanned on the CheckScannerTM.

\subsection{HPV E6/E7 mRNA Expression (NucliSENS EasyQ HPV} Assay). A commercial real-time NucliSENS EasyQ assay (NucliSENS EasyQ HPV 1.1, bioMérieux Hellas S.A, cat no. 290003) was performed for the qualitative detection of HPV E6/E7 mRNA of five hrHPV types $(16,18,31,33$, and 45) according to the manufacturer's instructions. Firstly, three premixes were made by adding reagent sphere diluent (Tris$\mathrm{HCl}, 45 \%$ DMSO) into reagent spheres (nucleotides, dithiotreitol, and $\mathrm{MgCl} 2$ ). In each premix, we added U1A/HPV 16, HPV 33/45, or HPV 18/31 primer and molecular beacon mixes, $\mathrm{KCl}$ stock solution, and NASBA water. Secondly, $10 \mu \mathrm{L}$ of this premix was distributed to each well in a reaction plate, and the addition of $5 \mu \mathrm{L}$ RNA followed. The plates were incubated for 4 minutes at $65^{\circ} \mathrm{C}$ to destabilize secondary structures of RNA, followed by cooling down to $41^{\circ} \mathrm{C}$. The reaction was started by addition of enzymes (AMV-RT, RNase H, T7 RNA polymerase, and bovine serum albumin) and measured in real time using the Lambda FL 600 fluorescence reader (Bio-Tek, Winooski, VT) at $41^{\circ} \mathrm{C}$ for 2 hours and 30 minutes.

2.6. Statistical Analysis. Our data were analyzed using SAS v9.0. Absolute and relative frequencies were used to present the HPV prevalence according to age and histology. Chisquared tests were performed to assess the statistical significance of any differences in prevalence. $t$-test was used, along with relevant descriptive statistics (mean value, standard deviation, and 95\% confidence interval for the mean value) to compare the average age among patients depending on the prevalence of HPV and histology. In all the statistical tests, $5 \%$ level of significance was used. Concordance between DNA and mRNA tests was evaluated using the Cohen's kappa statistic.

\section{Results}

3.1. Vaginal Intraepithelial Neoplasia and Vaginal Squamous Cell Carcinoma. This group consisted of 18 patients with VAIN (mean age 46.2 years) and 4 patients with SCCs (mean age of 61.3 years). 8 VAIN cases were classified as VAIN I 


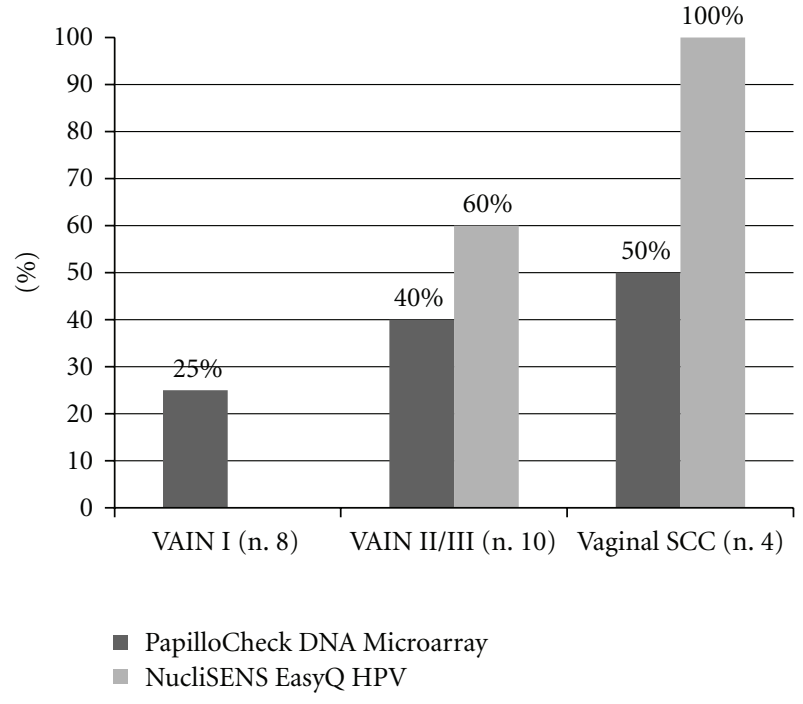

Figure 1: Prevalence of the hr HPV genotypes (16, 18, 31, 33, and 45) detected by both PapilloCheck DNA Microarray and NucliSENS EasyQ HPV assay according to histological status of samples of vagina.

and 10 as VAIN II/III. HPV infection was detected in $56 \%$ of VAIN (10/18) and in 50\% of vaginal SCCs (2/4). Detectable HPV DNA from at least one of the 24 genotypes was found in $75 \%(6 / 8)$ of cases of VAIN I and $40 \%(4 / 10)$ of VAIN II/III. In VAIN cases, the presence of HPV infection was strongly associated with younger patient age (38.7 versus 55.6 years, $P=0.006$ ).

hrHPV types were found in 70\% (7/10) and lrHPV types in $30 \%(3 / 10)$ of VAIN cases. Only hrHPVs were detected in vaginal SCCs $(2 / 2)$. Multiple HPV types were present only in one case (one VAIN II/III sample contained HPV 33 and 53).

The commonest HPV genotype was HPV 42 for VAIN I samples (3/6 cases, 50\%), followed by HPV 16 (2/6 cases, $33.3 \%$ ) and HPV 39 (1/6 cases, 16.7\%), while HPV16 and HPV33 were the most common types for VAIN II/III (2/4 cases, 50\% each). HPV 16 was the only type associated with HPV-infected vaginal SCCs (2/2 cases, $100 \%)$.

Regarding the hrHPV types 16, 18, 31, 33, and 45, 33.3\% $(6 / 18)$ of the VAIN and $50 \%$ of vaginal SCCs were HPV DNA positive for at least one of the above types. The detection rates of the five hrHPV types in samples from women with different grades of VAIN and SCCs are provided in Figure 1.

All vaginal SCCs $(4 / 4)$ and $60 \%(6 / 10)$ of VAIN II/III were positive for HPV E6/E7 mRNA expression. This was statistically significantly higher than VAIN I samples, where no HPV E6/E7 mRNA expression was detected $(P=0.01$ and $P=0.002$ ), respectively (Figure 1 ).

The expression pattern for hrHPV types 16, 18, 31, 33, and 45 , according to VAIN grade and SCCs, is summarized in Table 1.

The concordance between the HPV DNA test (PapilloCheck DNA Microarray) and HPV E6/E7 mRNA test (NucliSENS EasyQ HPV assay) results was poor for patients with VAIN I $(75 \%$; kappa $=0.00)$ and vaginal SCCs $(50 \%$; kappa
Table 1: Distribution of different HPV types detected by NucliSENS EasyQ HPV assay.

\begin{tabular}{|c|c|c|c|c|c|}
\hline \multirow[t]{2}{*}{ Histology result } & \multicolumn{5}{|c|}{ HPV types } \\
\hline & HPV16 & HPV18 & HPV31 & HPV33 & HPV45 \\
\hline \multicolumn{6}{|l|}{ VAIN I } \\
\hline VAIN II/III & 4 & & & 2 & \\
\hline Vaginal SCCs & 4 & & & & \\
\hline Total $(n .10)$ & 8 & & & 2 & \\
\hline VIN I & 4 & & & & \\
\hline VIN II/III & 6 & & & & 2 \\
\hline Vulvar SCCs & 3 & & & 2 & \\
\hline Total (n.17) & 13 & & & 2 & 2 \\
\hline
\end{tabular}

Distribution of the five high-risk HPV types determined by NucliSENS EasyQ HPV assay in the vaginal and vulvar tissue samples.

$=0.00)$, whereas it was good for patients with VAIN II/III $(80 \%$; kappa $=0.62)($ Table 2$)$.

3.2. Vulvar Intraepithelial Neoplasia and Vulvar Squamous Cell Carcinoma. We included 28 patients with VIN, half of which had a low-grade lesion (mean age 35 years) and 6 patients with vulvar SCCs (mean age 62.5 years). VIN cases were not associated with lichen sclerosus, differentiated vulvar intraepithelial neoplasia, or squamous cell hyperplasia. PapilloCheck DNA Microarray detected HPV infection in $71.4 \%$ of VIN samples $(20 / 28)$ and in $50 \%$ of vulvar SCCs (3/6). HPV DNA from at least one of the 24 genotypes was detected in $64.3 \%(9 / 14)$ of women with VIN I, and $78.6 \%$ of those with VIN II/III (11/14). In VIN cases, the presence of HPV infection was associated with younger patient age (31.7 versus 43.1 years, $P=0.001$ ).

PapilloCheck assay detected hrHPV infection in all VIN cases and vulvar SCCs. Multiple infection was detected in 5 cases (3 VIN I cases contained HPV 6/16, HPV 6/16/59 and $11 / 59$, resp., and 2 VIN II/III cases contained HPV 16/53 and HPV 16/51/66, resp.).

HPV16 and HPV59 were the most commonly observed for infected VIN I samples (4/9 cases each and one case with multiple infection HPV 6/16/59, 55.6\% each), while HPV16 was the commonest genotype for VIN II/III (9/11 cases, $81.8 \%)$ followed by types $18,51,52,53$, and $66(1 / 11$ cases, 9.1\% each). In HPV-positive vulvar SCCs, only HPV 16 was present $(3 / 3$ cases, $100 \%)$.

Regarding the hrHPV types 16, 18, 31, 33, and 45, $53.6 \%(15 / 18)$ of VIN and $50 \%$ of vulvar SCCs were HPV DNA positive for at least one of the above HPV types by PapilloCheck DNA Microarray. The detection rates of the five hrHPV types in samples from women with different grades of VIN and SCCs are provided in Figure 2.

$42.9 \%$ of VIN samples (12/28) and $83.3 \%$ of vulvar SCCs (5/6) were positive for HPV E6/E7 mRNA expression. There was a higher prevalence of E6 and E7 mRNA expression in patients with higher-grade lesions as shown in Figure 2. The difference in detection of E6/E7 mRNA expression between VIN I and vulvar SCCs was statistically significant $(P=$ 0.04). 
TABle 2: Concordance between HPV DNA test (PapilloCheck DNA Microarray) and HPV E6/E7 mRNA test (NucliSENS EasyQ HPV assay) by histological status of samples.

\begin{tabular}{|c|c|c|c|c|c|c|c|}
\hline & \multirow[t]{2}{*}{ No. of specimens } & \multicolumn{2}{|c|}{ Number of specimens positive with } & \multirow[t]{2}{*}{ Concordance* } & \multirow[t]{2}{*}{$\%$} & \multirow[t]{2}{*}{ Kappa value } & \multirow[t]{2}{*}{$P$} \\
\hline & & HPV DNA test & E6/E7 mRNA test & & & & \\
\hline VAIN I & 8 & 2 & 0 & $6 / 8$ & 75.0 & 0.00 & 1.00 \\
\hline VAIN II/III & 10 & 4 & 6 & $8 / 10$ & 80.0 & 0.62 & 0.08 \\
\hline Vaginal SCCs & 4 & 2 & 4 & $2 / 4$ & 50.0 & 0.00 & 1.00 \\
\hline VIN I & 14 & 5 & 4 & $13 / 14$ & 92.9 & 0.84 & 0.005 \\
\hline VIN II/III & 14 & 10 & 8 & $8 / 14$ & 57.1 & 0.09 & 1.00 \\
\hline Vulvar SCCs & 6 & 3 & 5 & $4 / 6$ & 66.7 & 0.33 & 1.00 \\
\hline
\end{tabular}

${ }^{*}$ The data represent the number of samples for which the results from PapilloCheck DNA Microarray and NucliSENS EasyQ HPV assay were concordant/total number of samples tested.

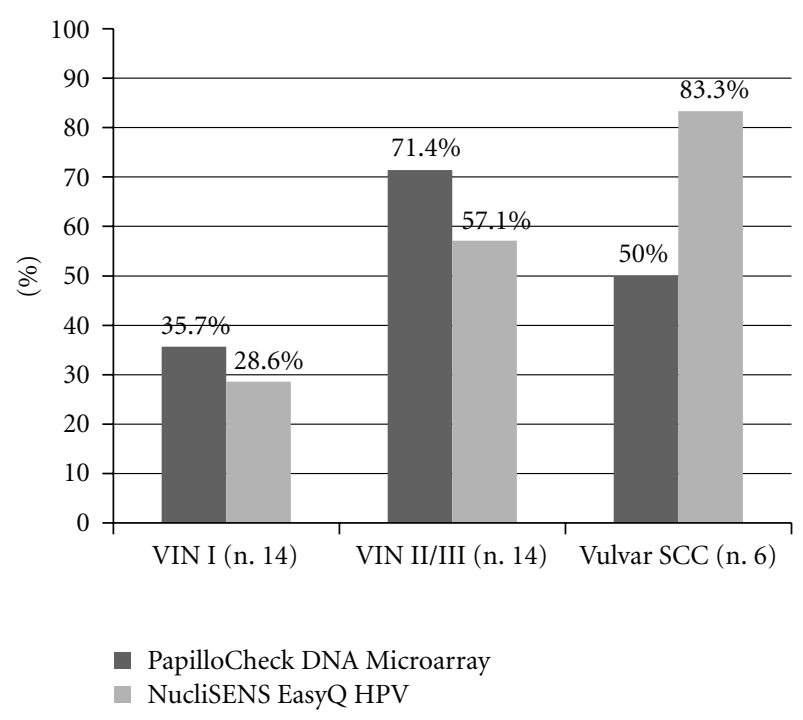

Figure 2: Prevalence of hr HPV genotypes (16, 18, 31, 33 and 45) detected by both PapilloCheck DNA Microarray and NucliSENS EasyQ HPV assay according to histological status of samples of vulva.

HPV16 was the commonest type revealed by NucliSENS EasyQ HPV assay for VIN I, VIN II/III, and vulvar SCCs (4/4 cases: $100 \%, 6 / 8$ cases: $75 \%$, and $3 / 5$ cases: $60 \%$, resp.) (Table 1).

The concordance between the HPV DNA test (PapilloCheck DNA Microarray) and HPV E6/E7 mRNA test (NucliSENS EasyQ HPV assay) results was very good for samples classified as having VIN I (92.9\%; kappa = 0.84) but was poor for patients with VIN II/III (57.1\%; kappa $=0.09)$. In the case of samples classified as having vulvar SCCs, the concordance was fair $(66.7 \%$; kappa $=0.33)$ (Table 2$)$.

\section{Discussion}

The goal of this study was to investigate HPV typing and HPV E6/E7 mRNA expression with intraepithelial neoplasia and squamous cell carcinomas of the vagina and vulva. This is the first study to report the association between HPV infection with oncogenic expression and vulvovaginal disease in Greek women.

The role of HPV infection in vulvar intraepithelial neoplasia and squamous cell carcinoma has been confirmed through multiple studies worldwide. Although a similar link exists in vaginal precancerous and cancerous lesions, this has not been firmly established. This in part is due to the fact that VAIN and vaginal carcinomas are less common than their vulvar and cervical counterparts, due to the absence of a susceptible transformation zone and the protective effect of the keratinized vaginal mucosa [7]. Furthermore, it is possible that a proportion of VAIN lesions remain undiagnosed as they are asymptomatic and not easy to visualize during a routine gynecological examination [5]. Nevertheless, we expect an outbreak of VAIN and VIN cases, as well as SCCs of the vulva and vagina, especially in younger women $[8,9]$. This is thought to be due to not only the rapid spread of HPV, but also the increased gynecological surveillance and improved diagnostic techniques, aimed at the identification of cervical lesions.

As mentioned above, several studies have previously described the HPV prevalence and genotype distribution in VIN and SCCs of the vulva $[3,4,10-16]$. The results of the current study are generally similar to worldwide VIN and vulvar SCCs data although some differences were observed. In our study, the overall HPV prevalence was $71.4 \%$ in VIN and $50 \%$ in vulvar carcinoma. A recent international metaanalysis of 14 studies on vaginal and 63 studies on vulvar lesions reported that the overall HPV prevalence in VIN was $84.0 \%$ and $40.4 \%$ in vulvar SCCs [5]. Similar results were reported by other studies which indicated HPV prevalence of $79.6 \%$ in VIN and $40.1 \%$ in vulvar SCCs $[15,16]$ (Table 4 ).

According to our results, hrHPV infection was the most frequently observed in VIN I cases. This is contrary to data obtained from an older study [3], where low-risk (lr) HPVs were the commonest types. HPV 16 and HPV 59 were the two most frequent genotypes in VIN I, accounting for $35.7 \%$, whereas in the recent international meta-analysis HPV 6 was found to be the commonest genotype [5]. HPV 16 was by far the commonest type in VIN II/III and vulvar SCCs in our study, accounting for $64.3 \%$, similar to other reports $[4,14]$ (Table 4). 
TABLe 3: Prevalence of HPV in intraepithelial neoplasia and carcinoma of the vagina, by study.

\begin{tabular}{|c|c|c|c|c|}
\hline Histologic type & $\begin{array}{l}\text { First } \\
\text { author }\end{array}$ & $\begin{array}{l}\text { No. of } \\
\text { cases }\end{array}$ & HPV test & $\begin{array}{l}\text { HPV prevalence for any } \\
\text { and specific genotypes }\end{array}$ \\
\hline \multicolumn{5}{|l|}{ VAIN I } \\
\hline & $\begin{array}{l}\text { Smith } \\
\text { (review) }\end{array}$ & 66 & PCR/hybrid capture assays & $\begin{array}{l}\text { Any HPV, } 98.5 \% \\
\text { Most common types; } 16(17.9 \%) \text {, } \\
18(17.9 \%)\end{array}$ \\
\hline & $\begin{array}{l}\text { De Vuyst } \\
\text { (meta- } \\
\text { analysis) }\end{array}$ & 107 & $\begin{array}{l}\text { PGMY reverse line blot/SPF } 10 \text { line probe } \\
\text { assay, blot hybridization }\end{array}$ & $\begin{array}{l}\text { Any HPV, } 100 \% \\
\text { Most common types; } 16(23.4 \%) \text {, } \\
56(11.0 \%), 51(8.8 \%)\end{array}$ \\
\hline \multicolumn{5}{|l|}{ VAIN II/III } \\
\hline & Smith & 166 & PCR/hybrid capture assays & $\begin{array}{l}\text { Any HPV, } 92.6 \% \\
\text { Most common type; } 16 \text { (65.8\%) }\end{array}$ \\
\hline & De Vuyst & 191 & $\begin{array}{l}\text { PGMY reverse line blot/SPF } 10 \text { line probe } \\
\text { assay, blot/southern hybridization, } \\
\text { restriction fragment analysis, sequencing }\end{array}$ & $\begin{array}{l}\text { Any HPV, } 90.1 \% \\
\text { Most common types; } 16(57.6 \%) \text {, } \\
18(6.9 \%), 58(5.9 \%)\end{array}$ \\
\hline \multicolumn{5}{|l|}{ Vaginal SCC } \\
\hline & Smith & 83 & PCR/hybrid capture assays & $\begin{array}{l}\text { Any HPV, } 65.5 \% \\
\text { Most common type; } 16 \text { (55.4\%) }\end{array}$ \\
\hline & De Vuyst & 136 & $\begin{array}{l}\text { Reverse line blot assay, INNO-LiPA HPV } \\
\text { genotyping, southern hybridization, } \\
\text { restriction fragment analysis, sequencing }\end{array}$ & $\begin{array}{l}\text { Any HPV, } 69.9 \% \\
\text { Most common types; } 16(53.7 \%) \text {, } \\
18(7.6 \%), 31(5.6 \%)\end{array}$ \\
\hline
\end{tabular}

$35.7 \%$ of VIN I samples harbored hrHPV $(16,18,31,33$, and 45 ) and this rose to $71.4 \%$ in VIN II/III samples. This is expected as women with hrHPV infection are more likely to progress to high-grade lesions. Interestingly, the percentage of hrHPV dropped to 50\% in vulvar SSCs. This suggests that the virus was present only at very low copy numbers and/or that only a specific region of viral DNA was integrated into the host's genome [17].

In our study, HPV prevalence in VAIN samples was 56\%. This was significantly lower than those reported by De Vuyst et al. (93,6\%) and Smith et al. (95.6\%). In vaginal SCCs, HPV prevalence was $50 \%$. This was lower but more comparable to those found in the studies mentioned above $(65.5 \%$ and $69.9 \%$, resp.) $[5,15]$ (Table 3 ).

In a worldwide meta-analysis, the most frequent genotypes were HPV 16, 56, and 51 in patients with VAIN I lesions, HPV 16, 18, and 58 in those with VAIN II/III, and HPV 16, 18, and 31 in those with vaginal SCCs [5] (Table 3). In our study, we detected, in decreasing order, HPV 42, 16, and 39 in VAIN I cases, HPV 16, 33, and 53 in VAIN II/III, cases, and HPV 16 in SCCs. It is interesting to note that HPV 18 was not identified in any of our VAIN or SCC samples, as opposed to what is seen elsewhere, and this may be a geographical variation that needs to be investigated further. Another variation, possibly attributed to our different sample population, was that HPV 42, a lrHPV type, was the most frequently identified type in VAIN I, whereas in the studies by De Vuyst et al. and Smith et al., no lrHPVs were detected in low-grade lesions $[5,15]$.

Contrary to what was observed in vulvar samples, the proportion of patients with detectable hrHPV $(16,18,31$, 33 , and 45) increased progressively as the grade of the vaginal lesion progressed.
Using the NucliSens EasyQ HPV assay, we investigated $\mathrm{HPV}$ oncoprotein expression in different grades of dysplasia and carcinoma. The results from E6/E7 mRNA test related well with the grade of lesion. The lowest rates of hrHPV types $(16,18,31,33$, and 45) E6/E7 mRNA expression were for patients with low-grade vulvar lesions (VIN I), whereas the higher rates were seen in high-grade lesions (VIN II/III), which is in accordance with what is seen in cervical lesions [18-20]. It is possible that VIN I lesions that have detectable E6/E7 mRNA expression are the ones with a potential to progress to higher-grade lesions and malignancy, and therefore, E6/E7 mRNA expression could be used as a screening marker for better surveillance in this subcategory of women. Interestingly, none of the five high-risk types E6/E7 mRNA expression was detected in low-grade vaginal lesions (VAIN I). The above findings probably suggest that VAIN I may not be strictly a precancerous disease, while at the same time, they reflect the transient nature of most HPV infections. On the contrary, VIN II/III, VAIN II/III, and vaginal and vulvar SCCs showed a high prevalence of E6/E7 mRNA expression. For VIN II/III in particular, the rates of E6/E7 mRNA expression that we found were significantly higher than what has been published previously (57.1 versus $38.1 \%$ ) [21].

In our series, there was a significantly higher detection of HPV 16 by NucliSens EasyQ HPV assay when compared to other hrHPV types for both vaginal and vulvar cases. This indicates that HPV 16 may be related to a different nature of persistent infection and oncoprotein expression in the vagina and vulva in comparison to HPV types 18, 31, 33, and 45 .

On the basis of DNA and mRNA assays, DNA from HPV was detected more frequently in vulvar low-grade lesions than E6/E7 mRNA expression. This data possibly reflects 
TABLE 4: Prevalence of HPV in intraepithelial neoplasia and carcinoma of the vulva, by study.

\begin{tabular}{|c|c|c|c|c|}
\hline Histologic type & $\begin{array}{l}\text { First } \\
\text { author }\end{array}$ & $\begin{array}{l}\text { No. of } \\
\text { cases }\end{array}$ & HPV test & $\begin{array}{l}\text { HPV prevalence for any } \\
\text { and specific genotypes }\end{array}$ \\
\hline \multicolumn{5}{|l|}{ VIN I } \\
\hline & $\begin{array}{l}\text { Smith } \\
\text { (review) }\end{array}$ & 71 & PCR/hybrid capture assays & $\begin{array}{l}\text { Any HPV, } 77.5 \% \\
\text { Most common types; } 6(23.8 \%), 16 \\
(14.3 \%), 56(1.7 \%)\end{array}$ \\
\hline & $\begin{array}{l}\text { De Vuyst } \\
\text { (meta- } \\
\text { analysis) }\end{array}$ & 90 & $\begin{array}{l}\text { PGMY reverse line blot/SPF } 10 \text { line probe } \\
\text { assay }\end{array}$ & $\begin{array}{l}\text { Any HPV, } 67.8 \% \\
\text { Most common types; } 6(22.4 \%), 16 \\
(9.8 \%), 11(9.0 \%)\end{array}$ \\
\hline & $\begin{array}{l}\text { Garland } \\
\text { (original } \\
\text { article) }\end{array}$ & 31 & Reverse line blot assay & $\begin{array}{l}\text { Any HPV, } 80.6 \% \\
\text { Most common types; } 6 \text { or } 11(64.5 \%)\end{array}$ \\
\hline \multicolumn{5}{|l|}{ VIN II/III } \\
\hline & Smith & 1340 & PCR/hybrid capture assays & $\begin{array}{l}\text { Any HPV, } 80.4 \% \\
\text { Most common types; } 16(71.2 \%), 33 \\
(7.7 \%)\end{array}$ \\
\hline & De Vuyst & 1061 & $\begin{array}{l}\text { PGMY reverse line blot/SPF } 10 \text { line probe } \\
\text { assay, sequencing, southern hybridization, } \\
\text { restriction fragment-length polymorphism } \\
\text { analysis }\end{array}$ & $\begin{array}{l}\text { Any HPV, } 85.3 \% \\
\text { Most common types; } 16(71.9 \%), 33 \\
(8.0 \%), 18(5.0 \%)\end{array}$ \\
\hline & Garland & 31 & Reverse line blot assay & $\begin{array}{l}\text { Any HPV, } 87.1 \% \\
\text { Most common types; } 16(64.5 \%), 6 \text {, or } \\
\text { HPV11 }(29 \%)\end{array}$ \\
\hline \multicolumn{5}{|l|}{ Vulvar SCC } \\
\hline & Smith & 1379 & PCR/hybrid capture assays & $\begin{array}{l}\text { Any HPV, } 40.1 \% \\
\text { Most common types; } 16(29.3 \%), 18 \\
(5.6 \%)\end{array}$ \\
\hline & De Vuyst & 1873 & $\begin{array}{l}\text { Reverse line blot hybridization, dot blot } \\
\text { hybridization, Roche HPV linear array }\end{array}$ & $\begin{array}{l}\text { Any HPV, } 40.4 \% \\
\text { Most common HPV types; } 16(32.2 \%) \text {, } \\
33(4.5 \%), 18(4.4 \%)\end{array}$ \\
\hline
\end{tabular}

an episomal state or low number of copies of the virus. However, E6/E7 mRNA expression in a number of VIN I indicates that hrHPV may be oncogenically active even before it produces detectable changes in the cell [17].

For vaginal high-grade lesions and carcinomas, as well as vulvar carcinomas, a higher rate of E6/E7 mRNA expression was observed, compared to HPV DNA. This suggests that the presence of E6/E7 oncoproteins is a specific marker for high-grade lesions. Interestingly, 2 cases of VAIN II/III, 1 case of VIN II/III, 2 cases of vaginal SCCs, and 2 cases of vulvar SCCs were positive only for mRNA expression. This may be explained by the fact that total viral DNA has been integrated to the host genome, and therefore, it cannot be detected by the DNA test. It is important to notice that in vulvar high-grade lesions a higher detection rate for HPV DNA was observed compared to E6/E7 mRNA expression. It is possible that these results were due to a very low level of viral transcriptional activity.

The sample in our study was relatively small, primarily due to the low incidence of vulvar and vaginal intraepithelial neoplasias and carcinomas. Thus, we can only provide a rough estimate of the relative importance of each HPV type with regards to vaginal and vulvar cancer and precancer in our population.
Another limitation of our study was that histology types of vulvar SCCs were not available, so a correlation between histology types and HPV infection was not possible. Nevertheless, it has been suggested that differentiated keratinizing SCCS, which occurs more frequently in elderly women, is not associated with HPV infection, whereas nonkeratinizing SCCS, which primarily affects younger women, is caused by hrHPV infection [22]. This was indirectly confirmed in our study, as HPV infection was more likely to be found in younger women.

\section{Conclusion}

This study described the detection rates and attribution of genital HPV types, as well as the E6/E7 mRNA expression of intraepithelial neoplasias and squamous cell carcinomas of the vagina and vulva in Greek women. In summary, our results showed that a very crucial percentage of HPV was associated with VIN, VAIN, and vaginal/vulvar SCCs, and HPV 16 accounted for most HPV-positive cases. The fact that some cases of vulvar low grade lesions were positive for E6/E7 mRNA expression is also of interest, as it may identify these lesions as more clearly precancerous. A striking increase especially in the incidence of VIN in young women has been 
reported in the last decades in some high-resources countries $[8,23,24]$.

Further research is required to better assess the role of mRNA testing as a molecular marker for vaginal and vulvar carcinogenesis.

\section{Conflict of Interests}

The authors declare that there is no conflict of interests.

\section{Acknowledgments}

The authors thank Ms. Marina Margaroni for her continued support and enthusiasm. This project was supported by the Regional Anticancer Oncology Hospital of Athens "St. Savvas", Athens, Greece.

\section{References}

[1] M. Stanley, "Pathology and epidemiology of HPV infection in females," Gynecologic Oncology, vol. 117, no. 2, pp. S5-S10, 2010.

[2] R. P. Insinga, K. L. Liaw, L. G. Johnson, and M. M. Madeleine, "A systematic review of the prevalence and attribution of human papillomavirus types among cervical, vaginal, and vulvar precancers and cancers in the United States," Cancer Epidemiology Biomarkers and Prevention, vol. 17, no. 7, pp. 1611-1622, 2008.

[3] M. Srodon, M. H. Stoler, G. B. Baber, and R. J. Kurman, "The distribution of low and high-risk HPV types in vulvar and vaginal intraepithelial neoplasia (VIN and VaIN)," The American Journal of Surgical Pathology, vol. 30, no. 12, pp. 1513-1518, 2006.

[4] B. C. Sutton, R. A. Allen, W. E. Moore, and S. T. Dunn, "Distribution of human papillomavirus genotypes in invasive squamous carcinoma of the vulva," Modern Pathology, vol. 21, no. 3, pp. 345-354, 2008.

[5] H. De Vuyst, G. M. Clifford, M. C. Nascimento, M. M. Madeleine, and S. Franceschi, "Prevalence and type distribution of human papillomavirus in carcinoma and intraepithelial neoplasia of the vulva, vagina and anus: a meta-analysis," International Journal of Cancer, vol. 124, no. 7, pp. 1626-1636, 2009.

[6] IARC, Monographs on the Evaluation of Carcinogenic Risks to Humans, Human Papillomaviruses, vol. 90, IARC Press, Lyon, France, 2007.

[7] M. L. Diaz, "Prevention of cervical, vaginal, and vulval cancers: role of the quadrivalent human papillomavirus $(6,11$, $16,18)$ recombinant vaccine," International Journal of Women's Health, vol. 1, no. 1, pp. 119-129, 2009.

[8] E. A. Joura, A. Losch, M. G. Haider-Angeler, G. Breitenecker, and S. Leodolter, "Trends in vulvar neoplasia: increasing incidence of vulvar intraepitheliai neoplasia and squamous cell carcinoma of the vulva in young women," Journal of Reproductive Medicine for the Obstetrician and Gynecologist, vol. 45, no. 8, pp. 613-615, 2000.

[9] H. Li, W. H. Zhang, L. Y. Wu, R. Znang, and P. Bai, "Clinicopathologic study of 24 patients with vulvar intraepithelial neoplasia III," Zhonghua Zhong Liu Za Zhi, vol. 27, no. 5, pp. 306-308, 2005.

[10] J. J. Carter, M. M. Madeleine, K. Shera et al., "Human papillomavirus 16 and $18 \mathrm{~L} 1$ serology compared across anogenital cancer sites," Cancer Research, vol. 61, no. 5, pp. 1934-1940, 2001.

[11] A. P. Pinto, M. C. Lin, G. L. Mutter, D. Sun, L. L. Villa, and C. P. Crum, "Allelic loss in human papillomavirus-positive and -negative vulvar squamous cell carcinomas," The American Journal of Pathology, vol. 154, no. 4, pp. 1009-1015, 1999.

[12] Y. T. Kim, N. F. Thomas, T. D. Kessis, E. J. Wilkinson, L. Hedrick, and K. R. Cho, "p53 mutations and clonality in vulvar carcinomas and squamous hyperplasias: evidence suggesting that squamous hyperplasias do not serve as direct precursors of human papillomavirus-negative vulvar carcinomas," Human Pathology, vol. 27, no. 4, pp. 389-395, 1996.

[13] B. J. Monk, R. A. Burger, F. Lin, G. Parham, S. A. Vasilev, and S. P. Wilczynski, "Prognostic significance of human papillomavirus DNA in vulvar carcinoma," Obstetrics \& Gynecology, vol. 85, no. 5, pp. 709-715, 1995.

[14] S. M. Garland, R. P. Insinga, H. L. Sings, R. M. Haupt, and E. A. Joura, "Human papillomavirus infections and vulvar disease development," Cancer Epidemiology Biomarkers and Prevention, vol. 18, no. 6, pp. 1777-1784, 2009.

[15] J. S. Smith, D. M. Backes, B. E. Hoots, R. J. Kurman, and J. M. Pimenta, "Human papillomavirus type-distribution in vulvar and vaginal cancers and their associated precursors," Obstetrics \& Gynecology, vol. 113, no. 4, pp. 917-924, 2009.

[16] D. Bryant, N. Rai, G. Rowlands et al., "Human papillomavirus type distribution in vulvar intraepithelial neoplasia determined using PapilloCheck DNA microarray," Journal of Medical Virology, vol. 83, no. 8, pp. 1358-1361, 2011.

[17] P. Cattani, G. F. Zannoni, C. Ricci et al., "Clinical performance of human papillomavirus E6 and E7 mRNA testing for highgrade lesions of the cervix," Journal of Clinical Microbiology, vol. 47, no. 12, pp. 3895-3901, 2009.

[18] I. Kraus, T. Molden, R. Holm et al., "Presence of E6 and E7 mRNA from human papillomavirus types 16, 18, 31, 33, and 45 in the majority of cervical carcinomas," Journal of Clinical Microbiology, vol. 44, no. 4, pp. 1310-1317, 2006.

[19] K. Sotlar, H. C. Selinka, M. Menton, R. Kandolf, and B. Bültmann, "Detection of human papillomavirus Type 16 E6/E7 oncogene transcripts in dysplastic and nondysplastic cervical scrapes by nested RT-PCR," Gynecologic Oncology, vol. 69, no. 2, pp. 114-121, 1998.

[20] S. Nakagawa, H. Yoshikawa, T. Yasugi et al., "Ubiquitous presence of E6 and E7 transcripts in human papillomaviruspositive cervical carcinomas regardless of its type," Journal of Medical Virology, vol. 62, no. 2, pp. 251-255, 2000.

[21] P. Hillemanns and X. Wang, "Integration of HPV-16 and HPV-18 DNA in vulvar intraepithelial neoplasia," Gynecologic Oncology, vol. 100, no. 2, pp. 276-282, 2006.

[22] H. P. van de Nieuwenhof, I. A. M. van der Avoort, and J. A. de Hullu, "Review of squamous premalignant vulvar lesions," Critical Reviews in Oncology/Hematology, vol. 68, no. 2, pp. 131-156, 2008.

[23] P. L. Judson, E. B. Habermann, N. N. Baxter, S. B. Durham, and B. A. Virnig, "Trends in the incidence of invasive and in situ vulvar carcinoma," Obstetrics \& Gynecology, vol. 107, no. 5, pp. 1018-1022, 2006.

[24] R. W. Jones, J. Baranyai, and S. Stables, "Trends in squamous cell carcinoma of the vulva: the influence of vulvar intraepithelial neoplasia," Obstetrics \& Gynecology, vol. 90, no. 3, pp. 448-452, 1997. 


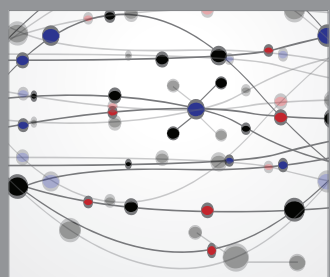

The Scientific World Journal
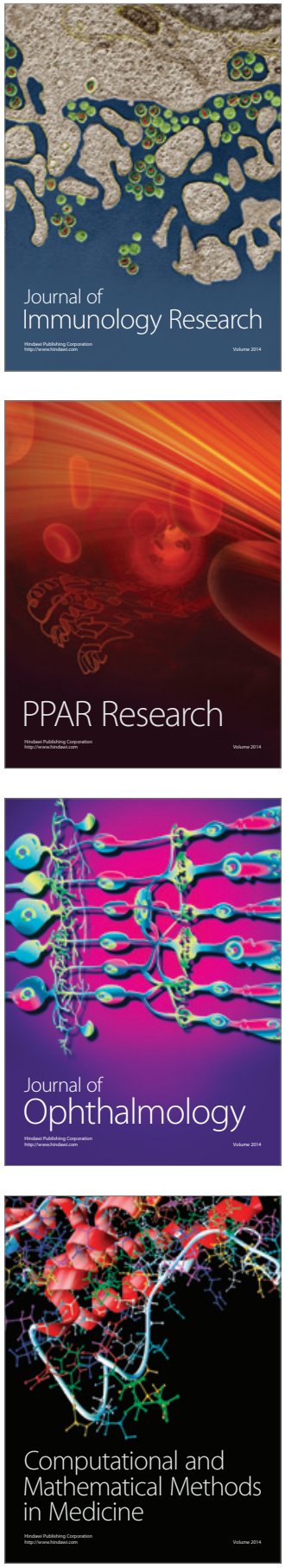

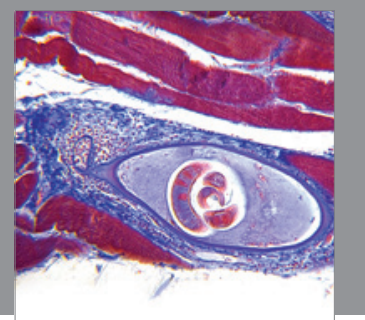

Gastroenterology

Research and Practice
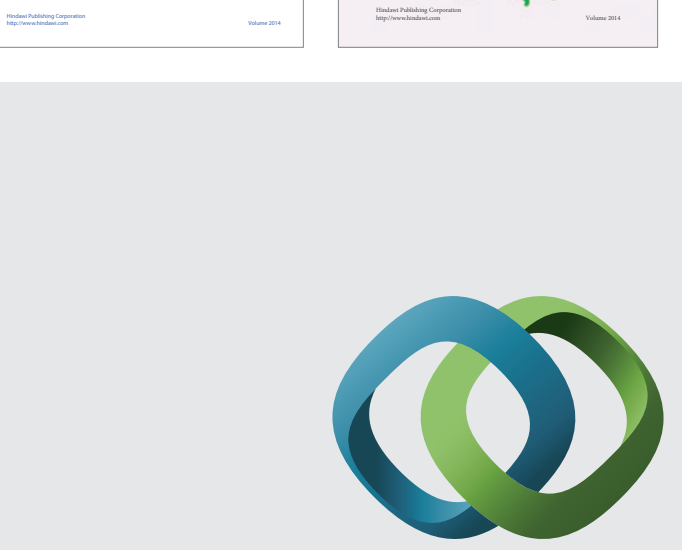

\section{Hindawi}

Submit your manuscripts at

http://www.hindawi.com
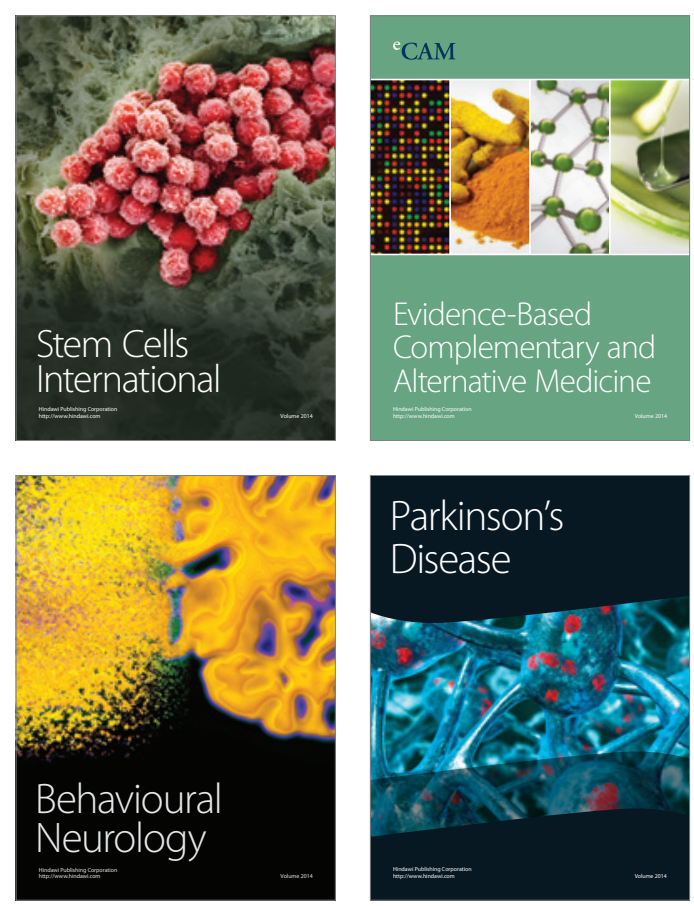

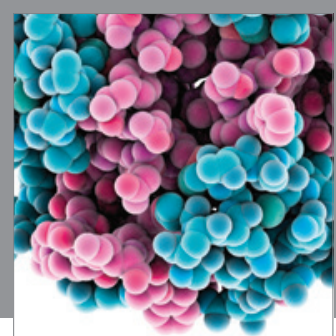

Journal of
Diabetes Research

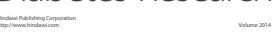

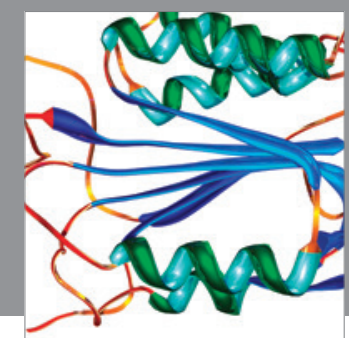

Disease Markers
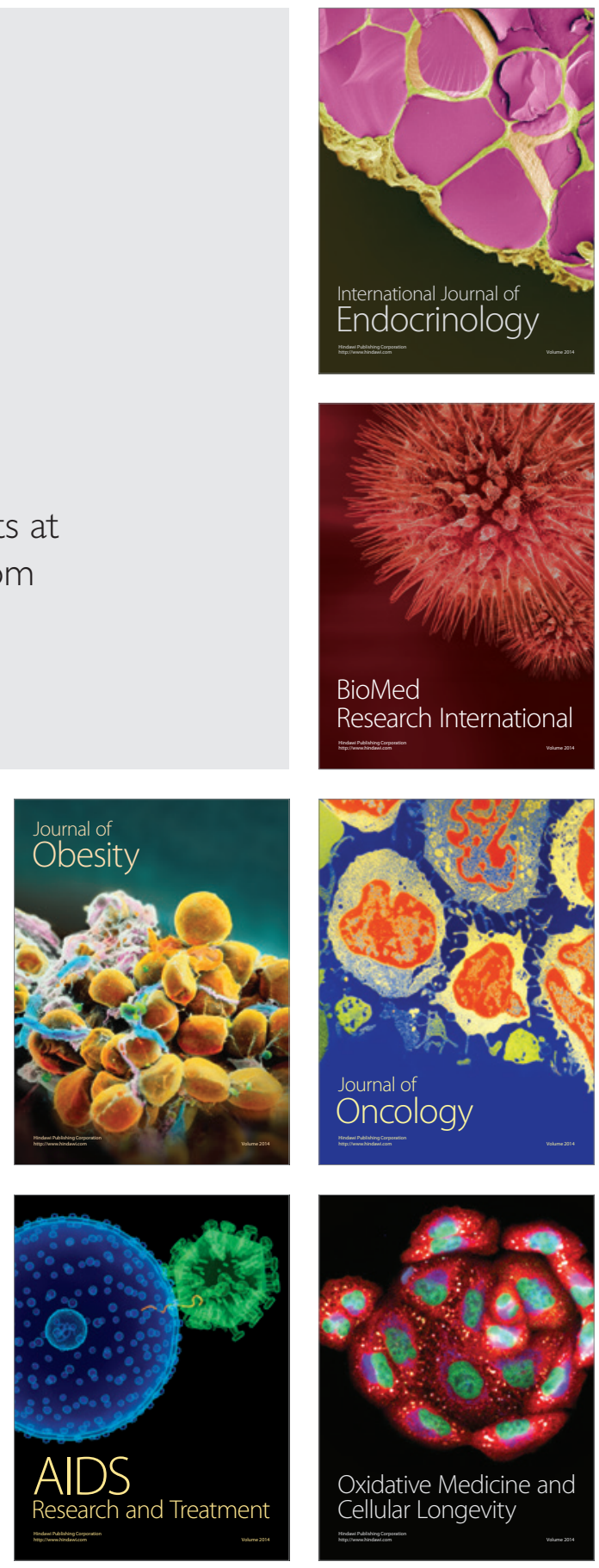